\title{
Effects of Silver Nanoparticles Synthesize From Ficus Benjamina on Normal Cells and Cancer Cells
}

\author{
Chittaranjan Bhakat ${ }^{1}$, Gaurav Chetal $^{2}$, Puja Sarkar ${ }^{2}$, Prasoon Pal Singh ${ }^{1}$, \\ Spoorthy N Babu ${ }^{2}$, Abhinav Reddy. $\mathrm{K}^{2}$ \\ ${ }^{I}$ Nanotechnology Department, International Institute of Information Technology, Pune, India. \\ ${ }^{2}$ Biotechnology Department, International Institute of Information Technology, Pune, India.
}

\begin{abstract}
In this article we report the effect of silver nanoparticles which were synthesize from Ficus Benjamina leaves (Green Synthesis) which was administered to normal body cells (HEK293) and cervical cancer cells (HeLa) in vitro to evaluate its possible apoptotic (anti-cancer) potentials. Silver nanoparticles are obtained from its precursor; silver nitrate $\left(\mathrm{AgNO}_{3}\right)$ by rapid reduction process using Ficus Benjamina leaves extract. Nanoparticles are found to be 20-30 $\mathrm{nm}$ in size and the reaction is accomplished by microwave reduction method and thermal heating method. Formation of silver and gold nanoparticles was confirmed by $u v$-vis spectrophotometer and scanning tunneling microscope.
\end{abstract}

Keywords - Apoptosis, Cervical cancer cells, Ficus Benjamina, Silver nanoparticles.

\section{Introduction}

Silver nanoparticles are the most stable metal nanoparticles; during the past decades colloidal silver nanoparticles have received significant research attention, both due to their unique physical and chemical properties, and promising applications [1,2,3,4]. Green synthesis of nanoparticles usually ranging from 1-100 $\mathrm{nm}$ is an emerging area of nanoscience and nanotechnology. Mostly properties of the solid depends on the size range over which they are measured i.e. size dependent property [5]. The recent interest of silver nanoparticles is propelled by both the advancement in our scientific understanding of their synthesis and physical properties as well as their possibilities of potential applications in the field of chemical and biological sensing [6,7,8], cancer treatment [9], catalysts [10,11], drug delivery [12], electronics and optoelectronic devices [13], antimicrobial activity [14], colloidal dispersion of silver nanoparticles, from colorless solution to light yellow to dark yellow to brown it appear when light interact with matter its optical properties change i.e. the size dependence color of colloidal gold is simply a consequence of how light interact with matter $[15,16]$. Colloidal silver nanoparticles are generally produced by the reduction of silver salt $\left(\mathrm{AgNO}_{3}\right)$ in an appropriate solvent, usually stabilizing agent is also added to prevent the particles from agglomeration, most frequently thiols modified ligands are used as stablishing agents for the formation of Ag naoparticles (Ag NPs). Biosynthesis of nanoparticles by plant extracts is currently under exploitation [17]. Thermal factor affect the size and uniformity of nanoparticles [18] so by controlling the temperature we can prevent the growth of nanoparticles.

Cervical cancer is caused by the Human Papilloma Virus (HPV), which forms warts in the throat and genital area. Although it is the one of the most prevalent cancer in India, it is also the most preventable cancer through screening and treatment of pre-cancerous lesion and the use of vaccines. Natural products are being tested for the treatment of cancer as conventional cancer treatments such as chemotherapy destroy cancerous as well as healthy cells.

Thus, in the present work, we report the effect of silver nanoparticles synthesize from Ficus Benjamina on normal cells and cervical cancer cells of body.

\section{Experimental}

Materials selection: Silver Nitrate $\left(\mathrm{AgNO}_{3}\right) 15 \mathrm{ml}$ of $1 \mathrm{mM}$, fresh green Ficus Benjamina crushed leaves, Media replenish \& subculture.

Synthesis of Silver Nanoparticles

For the synthesis of silver nanoparticles $15 \mathrm{ml}$ and $20 \mathrm{ml}$ of silver nitrate solution was mixed with $1 \mathrm{ml}$ and $2 \mathrm{ml}$ of crushed leaves extract of Ficus Benjamina respectively. It was then subject to the reduction at $15 \mathrm{psi}$ and $121^{\circ} \mathrm{C}$ in an autoclave. This process is known as solvothermal method [19].

Media replenish \& subculture:

Cell lines (HEK293 and HeLa) were procured from NCCS (National Centre for Cell Science), Pune. Fresh medium of DMEM (Dulbecco's Modified Eagle Medium) along with 10\% FBS (Fetal Bovine Serum) is added. When the plates are approximately $80 \%$ confluent, the old media is removed by pipette and is washed with 1ml of 1X PBS (Phosphate Buffer Saline) and discarded. Trypsin is added for the adherent cells to detach 

and FBS is added after 4-5min for neutralizing the action of trypsin. Collect the solution and centrifuge at 1000rpm in a $15 \mathrm{ml}$ falcon tube for $5 \mathrm{~min}$. Discard the supernatant and re-suspend the pellet in $1 \mathrm{ml}$ of media. Flush it thoroughly. Split the suspension in 1:2 ratios. If growth is very high, a maximum split of 1:6 can be done. Incubate them at $37^{\circ} \mathrm{C}$ and $5 \% \mathrm{CO}_{2}$. Maintain the plates by replenishing the media whenever required. When $80 \%$ confluency is reached, either passage the plate or cryopreserve accordingly.

\section{Preparation of working concentrations:}

The working concentrations were prepared at $50 \%, 25 \%, 12.5 \%, 6.25 \%, 3.125 \%$ and $1 \%$ by serial dilutions of the stock solution.

\section{Cell counting using Hemocytometer}

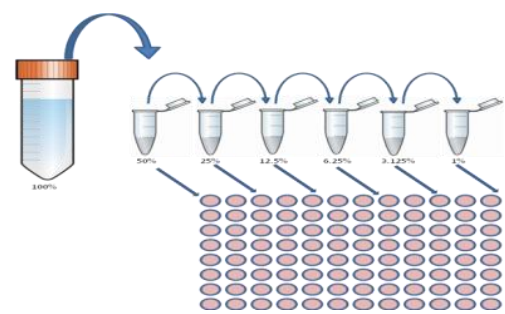

A plate of $80 \%$ confluency is considered. Collect the media and centrifuge to obtain a pellet. Discard the supernatant and resuspend the pellet by adding $1 \mathrm{ml}$ of media. Pipette out $10 \mu \mathrm{l}$ of this suspension and add it in $90 \mu \mathrm{l}$ of trypan blue. Mix the content thoroughly. Aspirate $10 \mu \mathrm{l}$ from the above content and load on both the sides of the hemocytometer. Observe under the microscope to count the cells. Using the following equation to estimate the amount of cells.

\section{In vitro analysis}

$$
\text { Total cells } / \mathrm{ml}=\text { Cell count } * 10^{4}(\text { volume of hemocytometer }) * 10(\text { dilution factor })
$$

12000cells/well are required. Accordingly, required amount of cell suspension is loaded in each well of 96 well plates. Each well is treated with its respective concentration by adding the working standard to make up to $200 \mu 1 /$ well. The plate is left for incubation at $37^{\circ} \mathrm{C}$ with $5 \% \mathrm{CO}_{2}$. The plate is incubated and morphological changes are observed at intervals of 3, 6, 12 and $24 \mathrm{hrs}$.

\section{Characterization Of Silver Nanoparticles}

Since the obtained nanoparticles are in the form of powders, they should be first dispersed in a liquid medium to form the suspension. If the nanoparticles are aggregated, they may lose some of their nanoscale properties. Therefore, before characterization the solution containing the powder samples should ultrasonicated for $15 \mathrm{~min}$ using ultrasonicating bath or ultrasonicating rod. All the nanoparticle samples were prepared in double distilled water as the solvent. The reaction solutions were characterized using UV Spectroscopy, scanning tunneling microscopy.

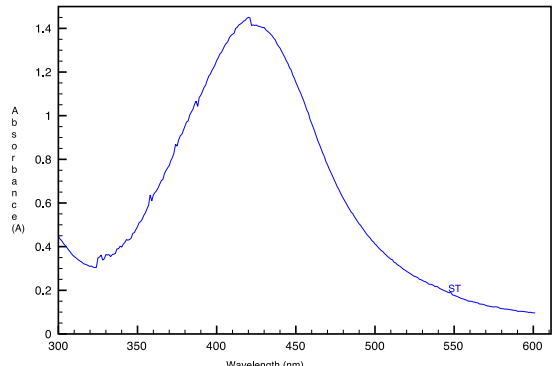

Fig-1 U-V Spectroscopy Graph for SNPs

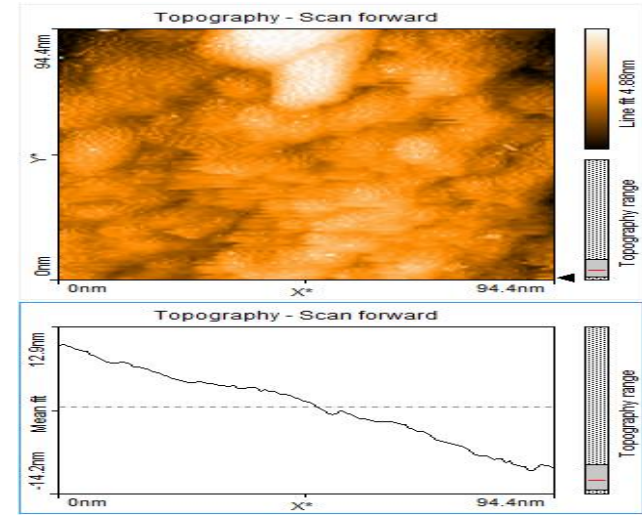

Fig-2 STM Images For SNPs

\section{Results \& Disscussion}

The basic reaction mechanism is the reduction of silver nitrates ion with Ficus Benjamina's leaves extract for silver nanoparticles synthesis. The formation of silver nanoparticles is conformed using uv-vis spectroscopy. Color change appears after the completion of the reaction, it is well known that silver nanoparticles exhibit yellowish brown color. Under uv-vis spectroscopy shows surface Plasmon absorption in the range of 415-440 nm (Fig-1). Fig-2 shows the STM image of silver nanoparticles. UV graph (Fig-1) shows broadening peak i.e. due to larger particles size. Sharpe peak indicates that the particle sizes are uniform.

Data, on the effect of the nanoparticles extracted from Ficus Benjamina on both Human Embryonic Kidney cells (HEK 393) and HeLa are illustrated from figures 1 to 8 at different time points. 

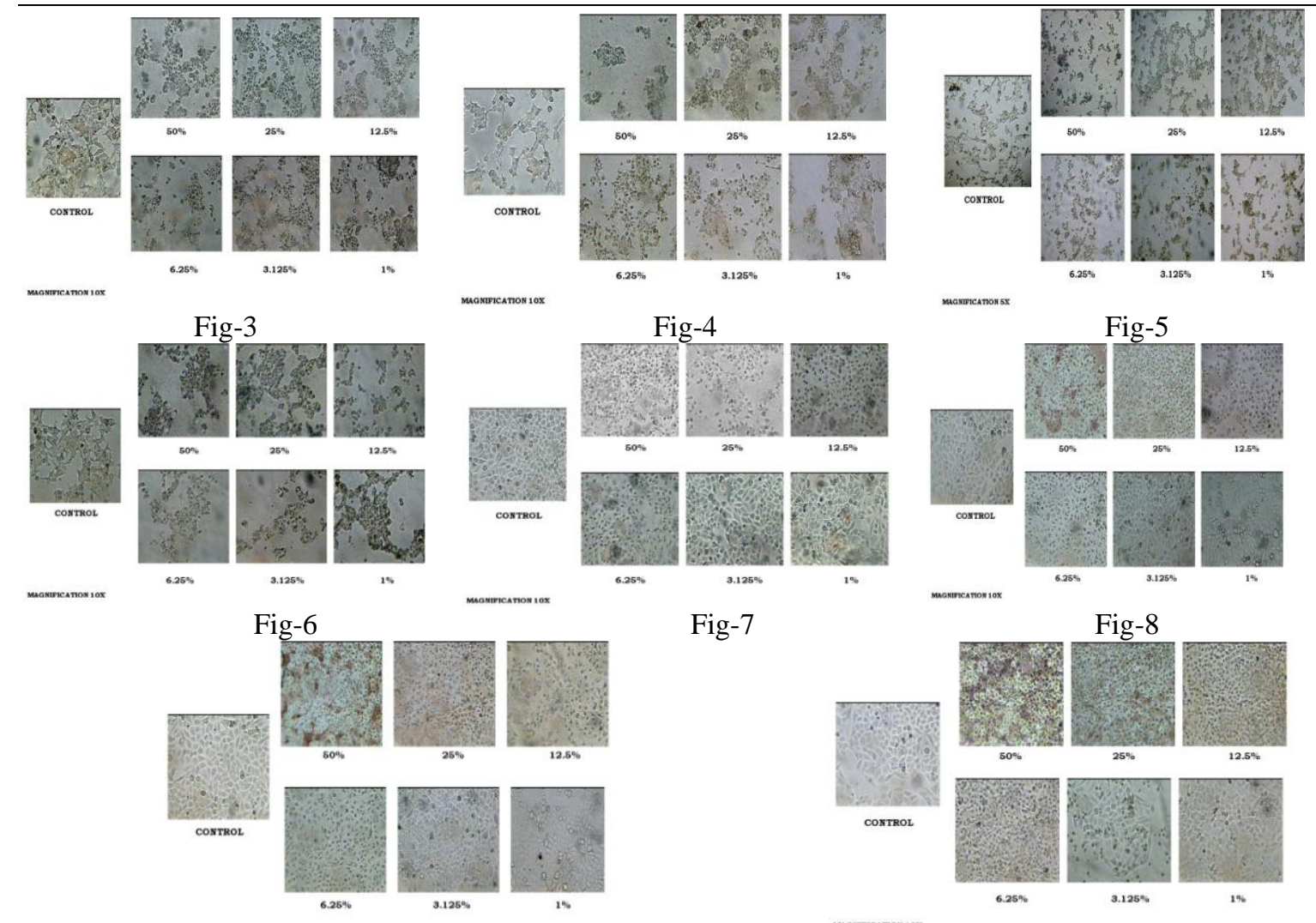

Fig-7

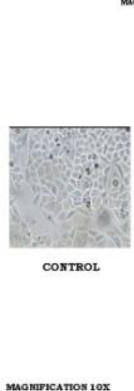

Fig-9

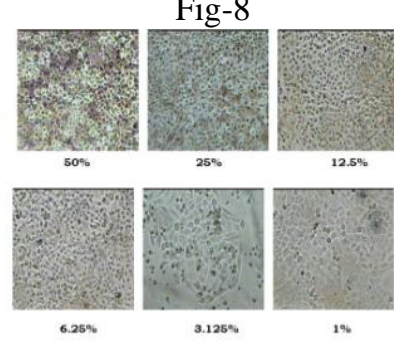

Fig-10

Figure 3 shows effect of the nanoparticle on hek 293 cells at 3 hrs with respect to control morphological changes were seen at all concentrations and cells appeared to be shrunk beginning with dark condensation of cellular components. Figure 4 shows effect of the nanoparticle on hek 293 cells at $6 \mathrm{hrs}$. The cells appeared to have thin cell membrane and cytoplasm is clear without any cell components visible when compared to control. They might have partially died. Figure 5 shows effect of the nanoparticle on hek 293 cells at $12 \mathrm{hrs}$. At 50\%, $25 \%$ and $12.5 \%$ shrinkage in cell size was observed along with damage in cell wall. Even in $1 \%$ the cell wall seems damaged but no change was seen in cell size. Figure 6 shows effect of the nanoparticle on hek 293 cells at $24 \mathrm{hrs}$. In comparison to control at $50 \%, 25 \%, 12.5 \%$ and $1 \%$ the cells were in stress while in $6.25 \%$ and $3.125 \%$ cells were dead. Figure 7 shows effect of the nanoparticle on hela cells at $3 \mathrm{hrs}$. Similar result was observed as of HEK-293 where cells shrunk with respect to control. No changes were seen for 3.125\% and $1 \%$. Figure 8 shows effect of the nanoparticle on hela cells at 6 hrs. The cells in $50 \%, 25 \%, 12.5 \%$, and $6.25 \%$ were even more condensed and shrunk with respect to control. The cells in $3.125 \%$ and $1 \%$ remained the same. Figure 9 shows effect of the nanoparticle on hela cells at $12 \mathrm{hrs}$. Cell death was observed at 50\%, 25\%, $12.5 \%$ and $6.25 \%$, while cells remained the same at $3.125 \%$ and $1 \%$ as compared to control. Figure 10 shows effect of the nanoparticle on hela cells at $24 \mathrm{hrs}$. As compared to cells in control no changes were observed in cells of $3.125 \%$ and $1 \%$.

For Human Embryonic kidney cells (HEK293) the nanoparticle from Ficus Benjamina showed varied effect at different concentrations. Over a period of $24 \mathrm{hrs}$. cell death was seen at $6.25 \%$ and $3.125 \%$ concentration. At higher concentrations i.e 50\%, $25 \%$ and $12.5 \%$ morphological changes, cell wall damage and cell size reduction had been observed within 6 hrs while at $1 \%$ concentration cell wall damage was visible to a lesser extent with respect to higher concentrations. On HeLa cells at higher concentrations i.e 50\%, 25\%, $12.5 \%$ and $6.25 \%$ concentrations cell death was observed over the duration of $24 \mathrm{hrs}$. and at lower concentration $3.125 \%$ and $1 \%$ concentrations, no changes were seen till $24 \mathrm{hrs}$. The effects of nanoparticle extracted from Ficus Benjamina have been studied on two cell lines, HeLa and HEK 293. They have shown different effects in these cell lines. The nanoparticles will be tested on other cell lines to check if they can be used as mode for treatment against cancer.

\section{Conclusion}

These synthesized silver nanoparticles using 'green' synthesis is used to check the effect of silver nanoparticles on normal cells and cancer cells presented. The techniques used for synthesis of Silver nanoparticles by exploiting under their specific conditions an solvothermal. Crushed leaves as well as extract of Ficus Benjamina's crushed leaves were used as reducing agents. The resultant nanoparticles exhibited the 
change in Plasmon Resonance. The results obtained by characterization of synthesized materials are compared and the study shows that the change in physical techniques in Green synthesis indirectly aftects on the orientation and nucleation of nanoparticles.

\section{Acknowledgement}

We thank H.O.D School of interdisciplinary science and technology Prof. Amit Patwardhan and also we thank H.O.D School of Biotechnology Prof. Prasad V.L.S. Burra for the freedom to do experiments.

\section{References}

[1] M. Tréguer-Delapierre, J. Majimel,S. Mornet, E. Duguet, S. Ravaine, "Synthesis of non-spherical gold nanoparticles", Pessac, France, Gold Bulletin, Pessac, France, 2008.

[2] Jose A. Lopez-Sanchez, Nikolaos Dimitratos, Ceri Hammond, Gemma L. Brett, Lokesh Kesavan, Saul White, Peter Miedziak, Ramchandra Tiruvalam, Robert L. Jenkins, Albert F. Carley, David Knight, Christopher J. Kiely \& Graham J. Hutchings, "Facile removal of stabilizer ligands from supported gold nanoparticles", Nature Chemistry 3, 551-556 (2011)

[3] Tsung-Hsuan Tsai, Soundappan Thiagarajan, Shen-Ming Chen, "Green Synthesis of Silver Nanoparticles Using Ionic Liquid and Application for the Detection of Dissolved Oxygen", willey, Electroanalysis 2010, 22, No. 6, 680 - 687

[4] Yu-Chieh Lu, Kan-Sen Chou, "A simple and effective route for the synthesis of nano-silver colloidal dispersions", Journal of the Chinese Institute of Chemical Engineers 39 (2008) 673-678.

[5] Charles P.Poole, Jr, Introduction to Nanotechnology, Wiley India (p) Ltd, 2006, p. 8-9

[6] Youngjin Kim, Robert C. Johnson, and Joseph T. Hupp*, "Gold Nanoparticle-Based Sensing of "Spectroscopically Silent" Heavy Metal Ions", American Chemical Society, vol 1. April 2001.

[7] Fredy Kurniawan, "New Analytical Applications Of Gold Nanoparticles", PhD thesis, Faculty of Chemistry and Pharmacy, University of Regensburg, Germany March 2008.

[8] Agnieszka Sobczak-Kupiec, Dagmara Malina, Małgorzata Zimowskaa, Zbigniew Wzorek, "Characterization Of Gold Nanoparticles For Various Medical Application”, Digest Journal of Nanomaterials and Biostructures, Vol. 6, No 2, April - June 2011, p. $803-808$.

[9] Radha Narayanan, "Recent Advances in Noble Metal Nanocatalysts for Suzuki and Heck Cross-Coupling Reactions", Molecules 2010, ISSN 1420-3049

[10] M.B. Cortie1 and E. van der Lingen2, "Catalytic Gold Nano-Particles", Materials Forum (2002) $26,1-14$.

[11] David Kisailus, Mark Najarina, James C. Weaver and Daniel E. Morse, 'Functional Gold Nanoparticles Mimics Catalyst Activity of a Polysiloxane Synthesizing Enzyme”, Advanced Materials 2005,17, 1234-1239.

[12] Wei Fu, Dinesh Shenoy, Jane Li, Curtis Crasto, Graham Jones, Charles Dimarzio, Srinivas Sridhar, and Mansoor Amiji, "Biomedical Applications of Gold Nanoparticles Functionalized Using Hetero-Bifunctional Poly(ethylene glycol) Spacer", Materials Research Society, Vol. 845,2005

[13] Daniel Huang,a Frank Liao,b Steven Molesa,b David Redinger,band Vivek Subramanian, "Plastic-Compatible Low Resistance Printable Gold Nanoparticles Conductors for Flexible Electronics", Journal of The Electrochemical Society, 150 7! G412-G417, 2003.

[14] Jun Sung Kim, Eunye Kuk, MS, Kyeong Nam Yu, Jong-Ho Kim, Sung Jin Park, Hu Jang Lee, Hyun Kim, Young Kyung Park, Yong Ho Park, Cheol-Yong Hwang, Yong-Kwon Kim, Yoon-Sik Lee, "Antimicrobial effects of silver nanoparticles", Nanomedicine: Nanotechnology, Biology, and Medicine 3 (2007) 95- 101.

[15] Dae Hong Jeong, PhD,b,4 Myung-Haing Cho,Vivek Sharma, Kyoungweon Park, Mohan Srinivasarao, "Colloidal dispersion of gold nanorods: Historical background, optical properties, seed-mediated synthesis, shape separation and self-assembly", Elsevier, 2009

[16] Anh-Tuan Le a, P.T. Huy a, Phuong Dinh Tam a, Tran Quang Huy b, Phung Dac Camb, A.A. Kudrinskiy c, Yu A. Krutyakov, "Green synthesis of finely-dispersed highly bactericidal silver nanoparticles via modified Tollens technique", elsviser 2009.

[17] Manish dubey, seema bhadauriaa, b.s. kushwah, "green synthesis of nanosilver particles from extract of eucalyptus hybrida (safeda) leaf”, digest journal of nanomaterials and biostructures, vol. 4, no. 3, september 2009, p. 537 - 543.

[18] Clemens Burda , Xiaobo Chen ,Radha Narayanan and Mostafa A. Fl-Sayed, " chemistry and properties of nanoparticles of different shape", American Chemical Society, Chemical Reviews Vol 105 No. 42005.

[19] Prasoon Pal Singh, Chittaranjan Bhakat, " green synthesis of silver and gold nanoparticles and its applications", International Journal of Applied Engineering Research, june 2012 